\title{
CINÉTICA DE INATIVAÇÃO DA POLIFENOLOXIDASE E PEROXIDASE DE ABÁCATE (Persea americana MILL.)
}

\author{
Kinetic of inactivation of polyphenoloxidase and peroxidase \\ of avocado (Persea americana Mill.)
}

\author{
Rúbia Caroline Luíz ${ }^{1}$, Talita Akemi Medeiros Hirata², Edmar Clemente ${ }^{3}$
}

\begin{abstract}
RESUMO
Extratos enzimáticos foram preparados a partir da polpa de abacate (Persea americana Mill.) dos cultivares Quintal, Fortuna e Choquete, em dois estádios de maturação (verde e maduro). A polpa de abacate $(150,00 \mathrm{~g})$ foi homogeneizada em liquidificador, com $300 \mathrm{~mL}$ de solução tampão fosfato de sódio $100 \mathrm{mM}$ em pH 7,4 para polifenoloxidase (PPO) e pH 6,0 para peroxidase (POD). A peroxidase ionicamente ligada foi extraída usando solução de $\mathrm{NaCl} 1,0 \mathrm{M}$, em tampão fosfato de sódio $100 \mathrm{mM} \mathrm{pH} \mathrm{6,0.} \mathrm{Para} \mathrm{o} \mathrm{estudo}$ da estabilidade térmica, os extratos foram submetidos a temperaturas de $60,65,70,75$ e $80^{\circ} \mathrm{C}$ e por períodos que variaram de 1 à 10 minutos e a atividade enzimática foi determinada por espectrofotometria $(\lambda=395 \mathrm{~nm}$ para PPO e $\lambda=460 \mathrm{~nm}$ para POD $)$. Pode-se observar que o declínio rápido da atividade das enzimas era maior nos primeiros quatro minutos e após esse período, com o aumento da temperatura e do tempo, a atividade continuou diminuindo, porém de forma mais lenta. A energia de ativação na faixa de temperatura estudada para as porções termolábil e termorresistente, apresentou valores dentro da faixa $12-100 \mathrm{kcal} / \mathrm{mol}$.
\end{abstract}

Termos para indexação: Abacate; polifenoloxidase; peroxidase; Persea americana.

\section{ABSTRACT}

Enzymatic extracts were prepared from the avocado pulp (Persea americana Mill.), using the cultivars Quintal, Fortuna and Choquete, in two different maturation stages (green and mature avocados). The avocado pulp $(150,00 \mathrm{~g})$ was homogenized in blender with $300 \mathrm{~mL}$ of sodium phosphate buffer $100 \mathrm{mM}$ at $\mathrm{pH} 7.4$ for polyphenoloxidase (PPO) and $\mathrm{pH} 6.0$ for peroxidase (POD). The peroxidase ionically bound was extracted using $\mathrm{NaCl}$ solution $1.0 \mathrm{M}$ in sodium phosphate buffer $100 \mathrm{mM} \mathrm{pH} 6.0$. For the study of the thermal stability the extracts were submitted at temperatures of $60,65,70,75$ and $80^{\circ} \mathrm{C}$ for periods that had a variation from 1 to 10 minutes and the enzymatic activity was determined using a spectrophotometer ( $\lambda=395 \mathrm{~nm}$ for PPO and $\lambda=460 \mathrm{~nm}$ for POD). It was possible to observe a fast decline of the enzyme activity in the first four minutes, after this period, with the increase of the temperature and time, the activity continued decreasing, however in a slower way. The activation energy in the studied temperature showed for the portions heat labile and heat resistant presented values inside $12-100 \mathrm{kcal} / \mathrm{mol}$.

Index terms: Avocado; polyphenoloxidase; peroxidase; Persea americana.

\section{(Recebido em 18 de julho de 2006 e aprovado em 22 de junho de 2007)}

\section{INTRODUÇÃO}

O abacate (Persea americana Mill.) é uma das frutas tropicais altamente valiosas e a expansão do seu consumo é justificado por suas qualidades organolépticas, seu valor nutritivo e a riqueza em suas vitaminas.

As reações enzimáticas são muito importantes em alimentos, delas depende não só a formação de compostos altamente desejáveis, mas podem também, ter conseqüências indesejáveis. As reações enzimáticas ocorrem não só no alimento natural, mas também durante seu processamento (BOBBIO \& BOBBIO, 1992).

Esses diferentes comportamentos são de utilidade para a indústria de alimentos, pois através deles se encontram as melhores soluções para o processamento (FORTUNADO, 2002). A inativação enzimática, através do tratamento térmico, é uma das soluções encontradas pela indústria alimentícia, sendo esse recurso utilizado principalmente na conservação do produto, em seu período de elaboração e armazenamento.

A otimização do processo térmico em alimentos que contenham enzimas naturais termorresistentes se torna difícil, pelo fato dessas enzimas apresentarem uma dependência com a temperatura, da mesma ordem de grandeza da dependência dos nutrientes e fatores de qualidade (cor, textura). No caso de enzimas, o objetivo do processamento térmico é sua inativação, porém no caso

\footnotetext{
${ }^{1}$ Engenheira de Alimentos - Laboratório de Bioquímica de Alimentos/DQI - Universidade Estadual de Maringá/UEM - Avenida Colombo, 5690, Zona 7 87020-900 - Maringá, PR - rubiaclaf@yahoo.com.br

2Engenheira de Alimentos - Laboratório de Bioquímica de Alimentos/DQI - Universidade Estadual de Maringá/UEM - Avenida Colombo, 5690, Zona 7 87020-900 - Maringá, PR - talitaakemi@yahoo.com.br

${ }^{3}$ Ph.D em Bioquímica de Alimentos - Universidade Estadual de Maringá/UEM - Avenida Colombo, 5690, Zona 7 - 87020-900 - Maringá, PR eclemente@uem.br
} 
de nutrientes e fatores de qualidade, o objetivo é sua retenção máxima (LUND, 1975). Segundo Lund (1975), no cálculo do processo térmico, baseado na inativação enzimática, a enzima mais termorresistente, que pode alterar a qualidade do produto durante o armazenamento, é usada como parâmetro no estabelecimento do processo. Entre esses alimentos encontram-se as frutas, que em geral contêm enzimas como peroxidase, pectinesterase e polifenoloxidase que são termorresistentes e são responsáveis pelas mudanças indesejáveis nos produtos enlatados dessas frutas (RAMASWAMAMY, 1989).

Quando um consumidor vai comprar um produto o primeiro impacto na qualidade é a aparência visual (EVANGELISTA, 1998). O controle do escurecimento enzimático durante o armazenamento e processamento de frutos é muito importante para a preservação da aparência natural dos mesmos. A preservação da polpa de abacate é afetada principalmente pelo escurecimento enzimático catalisado pela polifenoloxidase (PPO) e pelas reações degradativas da peroxidase (POD).

O escurecimento observado quando a maioria das frutas e dos vegetais é amassada, cortada ou triturada, é oriunda de reações catalisadas pela enzima polifenoloxidase (PPO). A ação dessa enzima em várias frutas e vegetais in natura acarreta perdas econômicas consideráveis, além de diminuição da qualidade nutritiva e alteração do sabor (ARAÚJO, 1999). A peroxidase age sobre as substâncias que produzem cores vivas na oxidação, mas ela pode promover uma grande variedade de reações de biodegradação e com isso apresenta um alto grau de versatilidade. De modo geral, é aceito que a peroxidase ao contrário de outras enzimas, que são inativadas pelo calor, permanece ativa. Logo, a atividade da peroxidase em muitas indústrias de alimentos é usada como índice de branqueamento (LING \& LUND, 1978).

No presente trabalho estudaram-se as enzimas POD, PPO em polpa de abacate, em três variedades e em estágios diferentes de maturação, avaliando a cinética de inativação dessas enzimas e a obtenção de informações que beneficiarão o setor industrial.

\section{MATERIAL E MÉTODOS}

Foram selecionadas três variedades de abacate: Quintal, Fortuna e Choquete, colhidas na Fazenda Escola da UEM, do Campus Regional do Noroeste, em Diamante do Norte/PR, e levados para o Laboratório de Bioquímica da UEM onde foram selecionadas, de acordo com o estádio de maturação (verde e maduro) e sanitizadas.

Todos os reagentes químicos utilizados foram de grau analítico.
Para a preparação do extrato bruto do abacate, homogeneizou-se $150,00 \mathrm{~g}$ da polpa de abacate com 300 $\mathrm{mL}$ de solução tampão fosfato de sódio $100 \mathrm{mM}$ ( $\mathrm{pH}$ 7,4 para a PPO e pH 6,0 para a POD) e em seguida os filtrados foram centrifugados (12.000rpm, a $4{ }^{\circ} \mathrm{C}$ por 20 minutos). Os sobrenadantes contendo PPO e POD solúvel foram armazenados a $-18^{\circ} \mathrm{C}$. Para a extração da peroxidase ionicamente (PIN) ligada utilizou-se o resíduo originário da centrifugação, quando da obtenção do extrato de peroxidase solúvel, POD. O resíduo foi ressuspenso em solução de $\mathrm{NaCl}$ 1,0 M em tampão fosfato de sódio $100 \mathrm{mM} \mathrm{pH} \mathrm{6,0} \mathrm{e} \mathrm{foi} \mathrm{novamente}$ centrifugado (12.000rpm, a $4^{\circ} \mathrm{C}$ por 20 minutos) e o sobrenadante, denominado PIN, armazenado a $-18^{\circ} \mathrm{C}$ e o resíduo descartado.

A atividade da PPO foi determinada pelo método descrito por Fujita (1995) e da POD pelo método descrito por Clemente (1998).

Os extratos enzimáticos concentrados foram submetidos a tratamento térmico nas temperaturas de $60^{\circ}$, $65^{\circ}, 70^{\circ}, 75^{\circ}$ e $80^{\circ} \mathrm{C}$, por períodos variando de 1 a 10 minutos, e, posteriormente, determinando-se a atividade enzimática por espectrofotometria.

Foram calculados os seguintes parâmetros cinéticos para a PPO e POD: D (Tempo de redução decimal), K (Constante de velocidade de inativação), Z (Fator de dependência da temperatura) e EA (Energia de ativação). Para o cálculo do tempo de redução decimal (D) e da constante de velocidade de inativação térmica $(\mathrm{K})$ utilizou-se o modelo descrito por Ling \& Lund (1978). Calculou-se a energia de ativação das porções termolábil e termorresistente baseada na metodologia descrita por Ramaswamy et al. (1989).

\section{RESULTADOS E DISCUSSÃO}

Antes dos extratos enzimáticos da polpa de abacate nos estádios de maturação verde e maduro serem submetidos ao tratamento térmico, as atividades das enzimas PPO, POD solúvel e PIN foram avaliadas. Possibilitando observar-se que a atividade enzimática da polifenoloxidase aumentou à medida que o fruto atingiu o climatério, apesar de que na variedade Choquete isso não ter sido observado. Demonstrando que a atividade enzimática pode variar, não somente entre frutos, mas entre variedades da mesma espécie. Além disso, observou-se que a variedade Choquete foi a que apresentou uma maior atividade para a enzima polifenoloxidase, no estádio de maturação verde, o que pode observar-se na tabela 1. 
Com o tratamento térmico dos extratos, verificou-se uma relação inversa entre a temperatura e o tempo de aquecimento, pois quanto mais alta a temperatura menor era o tempo de aquecimento necessário para a inativação térmica. Os resultados encontrados para inativação térmica da polifenoloxidase, peroxidase e peroxidase ionicamente ligada podem observar-se nas tabelas 2,3 e 4 respectivamente.

Para a enzima PPO, as três variedades analisadas obtiveram o mesmo comportamento em relação à inativação térmica, por exemplo, para o 'Quintal verde', onde após seis minutos de aquecimento a $60^{\circ}, 65^{\circ}$ e $70^{\circ} \mathrm{C}$ houve inativação de $10,85 \% ; 12,02 \%$ e $25,97 \%$, respectivamente, dessa enzima. A $75^{\circ}$ e $80^{\circ} \mathrm{C}$, após quatro minutos de aquecimento, inativou-se $32,56 \%$ e $38,37 \%$. Observou-se o mesmo comportamento para o 'Quintal maduro', após seis minutos de aquecimento a $60^{\circ}$ e $65^{\circ} \mathrm{C}$, a porcentagem de inativação foi de 17,75 e 26,70, respectivamente, enquanto que para as temperaturas de $70^{\circ}$, $75^{\circ}$ e $80^{\circ} \mathrm{C}$, após quatro minutos, a inativação foi de $49,62 \%$, $47,04 \%$ e $50,79 \%$, respectivamente. Para as variedades Quintal e Fortuna notou-se que a porcentagem de inativação aumentou à medida que os frutos atingiam o climatério, apresentando, portanto uma maior atividade enzimática.

Tanto para a peroxidase e peroxidase ionicamente ligada, analisadas apenas em uma variedade, o Choquete, observou-se que quanto maior a temperatura menor o tempo necessário para o declínio da atividade delas. Esse comportamento apresentou-se bem mais visível para a PIN, pois na polpa de abacate Choquete verde e maduro, após dez minutos de aquecimento a temperatura de $60{ }^{\circ} \mathrm{C}$ inativou apenas $8,08 \%$ e $9,40 \%$, respectivamente, enquanto que a $80^{\circ} \mathrm{C}$, em um tempo de 0,5 minutos a inativação foi de $28,19 \%$ e $20,27 \%$, respectivamente. Esses resultados estão de acordo com os encontrados por Fortunato (2002).

A atividade de peroxidase solúvel foi maior para os frutos no estádio verde do que no fruto maduro, sendo que a fração ionicamente ligada apresentou um resultado inverso, o que pode ser devido a uma maior participação da fração solúvel, na síntese de proteínas.

Foi comprovado, de um modo geral, o efeito da temperatura sobre o tempo de aquecimento necessário à inativação térmica da polifenoloxidase e da peroxidase (fração solúvel e ionicamente ligada), ou seja, quanto maior a temperatura menor o tempo de aquecimento necessário.

A peroxidase se comporta como sendo a enzima mais termorresistente, nos produtos de origem vegetal. Contudo nas frutas, por causa das condições mais ácidas, a peroxidase se apresenta menos estável, embora seja difícil sua inativação. Nos resultados encontrados, o máximo de porcentagem de inativação que se conseguiu, para a peroxidase foi de $34,17 \%$ a uma temperatura de $80{ }^{\circ} \mathrm{C}$, em um tempo de 10 minutos, para a variedade Choquete, no estádio de maturação verde.

Os resultados da inativação térmica dos extratos enzimáticos contendo PPO, POD e PIN para a fração termorresistente observam-se nas figuras 1,2 e 3, onde Log $(\% \mathrm{P})$ significa o logaritmo da porcentagem da atividade enzimática $(\mathrm{P})$ que permanece ativa ao longo do tempo, $\mathrm{e}$ com o aumento da temperatura.

Tabela 1 - Atividade de PPO, POD e PIN em polpa de abacate $(n=3)$.

\begin{tabular}{cccc}
\hline Variedade & PPO & POD & PIN \\
& $\Delta \mathrm{DO}_{395 \mathrm{~nm} \mathrm{min/mL}} \pm \delta$ & $\Delta \mathrm{DO}_{460 \mathrm{~nm} \text { min/mL }} \pm \delta$ & $\Delta \mathrm{DO}_{460 \mathrm{~nm} \text { min/mL }} \pm \delta$ \\
\hline Quintal Verde & $2,58 \pm 0,02$ & - & - \\
Quintal Maduro & $2,96 \pm 0,01$ & - & - \\
Fortuna Verde & $2,13 \pm 0,01$ & - & - \\
Fortuna Maduro & $2,40 \pm 0,02$ & $2,96 \pm 0,02$ & $3,01 \pm 0,01$ \\
Choquete Verde & $3,84 \pm 0,01$ & $2,85 \pm 0,01$ & $3,20 \pm 0,02$ \\
Choquete Maduro & $2,40 \pm 0,01$ & & - \\
\hline
\end{tabular}

$\mathrm{n}=$ número de repetições, $\delta=$ desvio padrão 
Tabela 2 - Média da inativação térmica da enzima PPO, em três variedades de abacate, em dois estádios de maturação $(n=3)$.

\begin{tabular}{|c|c|c|c|c|c|c|c|c|}
\hline \multirow{2}{*}{$\begin{array}{c}\text { Extrato } \\
\text { enzimático }\end{array}$} & Tempo(min) & 0 & 1 & 2 & 3 & 4 & 5 & 6 \\
\hline & Temperatura & \multicolumn{7}{|c|}{ \% de Inativação } \\
\hline \multicolumn{9}{|c|}{$60^{\circ} \mathrm{C}$} \\
\hline Quintal Verde & & 0 & 4,27 & 5,82 & 4,43 & 8,53 & 9,69 & 10,85 \\
\hline Quintal Maduro & & 0 & 5,26 & 9,38 & 12,33 & 11,47 & 13,40 & 17,75 \\
\hline Fortuna Verde & & 0 & 7,74 & 2,11 & 7,74 & 4,13 & 11,68 & 13,47 \\
\hline Fortuna Maduro & & 0 & 11,95 & 15,99 & 19,73 & 18,07 & 20,15 & 22,17 \\
\hline Choquete Verde & & 0 & 5,26 & 9,38 & 12,33 & 11,47 & 13,40 & 14,75 \\
\hline Choquete Maduro & & 0 & 13,14 & 20,17 & 13,48 & 21,66 & 21,67 & 22,59 \\
\hline \multicolumn{9}{|c|}{$65^{\circ} \mathrm{C}$} \\
\hline Quintal Verde & & 0 & 0,78 & 1,55 & 4,65 & 8,91 & 9,30 & 12,02 \\
\hline Quintal Maduro & & 0 & 2,66 & 8,80 & 10,16 & 12,25 & 20,93 & 26,70 \\
\hline Fortuna Verde & & 0 & 6,43 & 7,46 & 8,01 & 7,93 & 10,91 & 14,08 \\
\hline Fortuna Maduro & & 0 & 17,36 & 18,86 & 16,53 & 17,24 & 21,61 & 24,19 \\
\hline Choquete Verde & & 0 & 2,66 & 8,80 & 10,16 & 12,25 & 20,93 & 26,70 \\
\hline Choquete Maduro & & 0 & 19,05 & 19,84 & 23,01 & 31,86 & 32,03 & 38,52 \\
\hline \multicolumn{9}{|c|}{$70^{\circ} \mathrm{C}$} \\
\hline Quintal Verde & & 0 & 8,91 & 12,79 & 14,73 & 16,67 & 18,60 & 25,97 \\
\hline Quintal Maduro & & 0 & 21,40 & 22,65 & 39,54 & 49,62 & 60,15 & 54,68 \\
\hline Fortuna Verde & & 0 & 9,95 & 12,67 & 12,76 & 18,35 & 17,51 & 19,25 \\
\hline Fortuna Maduro & & 0 & 23,23 & 31,64 & 32,14 & 34,81 & 36,22 & 36,80 \\
\hline Choquete Verde & & 0 & 21,40 & 22,65 & 39,54 & 49,62 & 60,15 & 54,68 \\
\hline Choquete Maduro & & 0 & 22,46 & 24,21 & 26,04 & 31,31 & 35,19 & 42,51 \\
\hline \multicolumn{9}{|c|}{$75^{\circ} \mathrm{C}$} \\
\hline Quintal Verde & & 0 & 8,91 & 20,54 & 29,07 & 32,56 & 34,11 & 34,11 \\
\hline Quintal Maduro & & 0 & 0,78 & 21,5 & 38,73 & 47,04 & 49,20 & 54,80 \\
\hline Fortuna Verde & & 0 & 16,56 & 23,18 & 16,94 & 23,18 & 22,34 & 26,42 \\
\hline Fortuna Maduro & & 0 & 29,64 & 38,34 & 36,47 & 34,30 & 37,72 & 37,72 \\
\hline Choquete Verde & & 0 & 0,78 & 21,50 & 38,73 & 47,04 & 49,20 & 54,80 \\
\hline Choquete Maduro & & 0 & 24,13 & 27,41 & 28,04 & 30,28 & 36,52 & 45,46 \\
\hline \multicolumn{9}{|c|}{$80^{\circ} \mathrm{C}$} \\
\hline Quintal Verde & & 0 & 16,67 & 14,73 & 31,01 & 38,37 & 43,80 & 48,84 \\
\hline Quintal Maduro & & 0 & 12,74 & 25,33 & 44,90 & 50,79 & 56,74 & 59,26 \\
\hline Fortuna Verde & & 0 & 21,44 & 25,39 & 27,26 & 26,40 & 33,18 & 39,98 \\
\hline Fortuna Maduro & & 0 & 26,73 & 32,72 & 35,89 & 41,13 & 43,56 & 44,63 \\
\hline Choquete Verde & & 0 & 12,74 & 25,33 & 44,90 & 50,79 & 56,74 & 59,78 \\
\hline Choquete Maduro & & 0 & 28,95 & 24,38 & 45,67 & 54,24 & 53,49 & 55,16 \\
\hline
\end{tabular}

$\mathrm{n}=$ número de repetições 
Tabela 3 - Média da inativação térmica da enzima POD, na variedade Choquete, em dois estádios de maturação ( $\mathrm{n}=3)$.

\begin{tabular}{|c|c|c|c|c|c|c|c|}
\hline \multirow{2}{*}{$\begin{array}{c}\text { Extrato } \\
\text { enzimático }\end{array}$} & Tempo(min) & 0 & 0,5 & 1 & 3 & 6 & 10 \\
\hline & Temperatura & \multicolumn{6}{|c|}{$\%$ de Inativação } \\
\hline & $60^{\circ} \mathrm{C}$ & & & & & & \\
\hline Choquete Verde & & 0 & 5,57 & 11,45 & 14,73 & 13,90 & 17,70 \\
\hline Choquete Maduro & & 0 & 2,66 & 4,25 & 7,52 & 8,67 & 8,61 \\
\hline & $65^{\circ} \mathrm{C}$ & & & & & & \\
\hline Choquete Verde & & 0 & 8,62 & 10,23 & 17,92 & 19,28 & 20,27 \\
\hline Choquete Maduro & & 0 & 0,07 & 4,59 & 12,33 & 14,12 & 17,38 \\
\hline & $70^{\circ} \mathrm{C}$ & & & & & & \\
\hline Choquete Verde & & 0 & 9,89 & 17,05 & 20,05 & 19,91 & 21,56 \\
\hline Choquete Maduro & & 0 & 7,05 & 12,94 & 15,22 & 15,38 & 16,51 \\
\hline & $75^{\circ} \mathrm{C}$ & & & & & & \\
\hline Choquete Verde & & 0 & 14,68 & 18,98 & 24,75 & 22,85 & 26,46 \\
\hline Choquete Maduro & & 0 & 16,31 & 20,34 & 25,06 & 26,58 & 29,15 \\
\hline & $80^{\circ} \mathrm{C}$ & & & & & & \\
\hline Choquete Verde & & 0 & 16,72 & 18,34 & 27,73 & 31,84 & 34,17 \\
\hline Choquete Maduro & & 0 & 16,78 & 24,59 & 26,57 & 30,92 & 32,36 \\
\hline
\end{tabular}

$\mathrm{n}=$ número de repetições

Tabela 4 - Média da inativação térmica da enzima POD ionicamente ligada, em três variedades de abacate, em dois estádios de maturação $(n=3)$.

\begin{tabular}{|c|c|c|c|c|c|c|c|}
\hline \multirow{2}{*}{$\begin{array}{c}\text { Extrato } \\
\text { enzimático }\end{array}$} & Tempo(min) & 0 & 0,5 & 1 & 3 & 6 & 10 \\
\hline & Temperatura & \multicolumn{6}{|c|}{ \% de Inativação } \\
\hline & $60^{\circ} \mathrm{C}$ & & & & & & \\
\hline Choquete Verde & & 0 & 1,16 & 4,36 & 3,37 & 6,43 & 8,08 \\
\hline Choquete Maduro & & 0 & 3,84 & 8,08 & 6,37 & 9,11 & 9,40 \\
\hline & $65^{\circ} \mathrm{C}$ & & & & & & \\
\hline Choquete Verde & & 0 & 1,43 & 2,54 & 3,22 & 9,77 & 16,18 \\
\hline Choquete Maduro & & 0 & 4,66 & 8,90 & 9,31 & 10,81 & 9,38 \\
\hline & $70^{\circ} \mathrm{C}$ & & & & & & \\
\hline Choquete Verde & & 0 & 10,91 & 11,59 & 18,47 & 14,20 & 22,57 \\
\hline Choquete Maduro & & 0 & 15,66 & 19,55 & 21,99 & 29,45 & 31,00 \\
\hline & $75^{\circ} \mathrm{C}$ & & & & & & \\
\hline Choquete Verde & & 0 & 21,70 & 31,18 & 36,21 & 41,48 & 42,84 \\
\hline Choquete Maduro & & 0 & 16,85 & 20,68 & 21,96 & 27,05 & 34,82 \\
\hline & $80^{\circ} \mathrm{C}$ & & & & & & \\
\hline Choquete Verde & & 0 & 28,19 & 33,91 & 35,29 & 46,24 & 46,60 \\
\hline Choquete Maduro & & 0 & 20,27 & 22,47 & 28,70 & 33,68 & 40,00 \\
\hline
\end{tabular}

n= número de repetições 


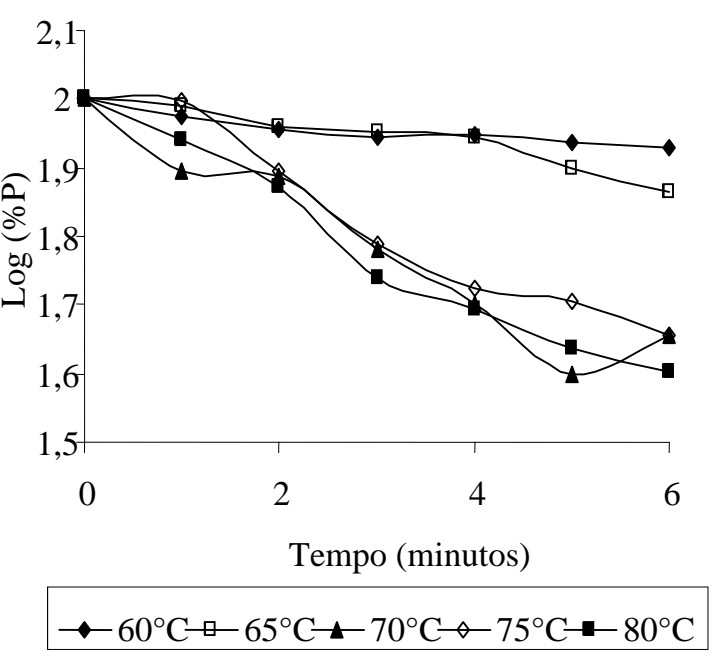

a)

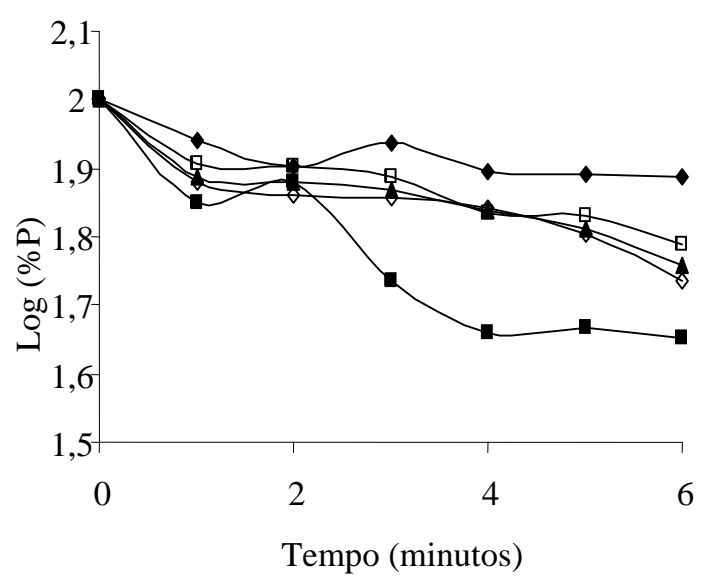

$60^{\circ} \mathrm{C}-65^{\circ} \mathrm{C} \neg-70^{\circ} \mathrm{C} \diamond-75^{\circ} \mathrm{C}-80^{\circ} \mathrm{C}$

b)

Figura 1 - Inativação térmica da PPO de polpa de abacate (Variedade Choquete) a 60, 65, 70, 75 e $80^{\circ} \mathrm{C}$. (a - Abacate Verde, b - Abacate Maduro).

2,05

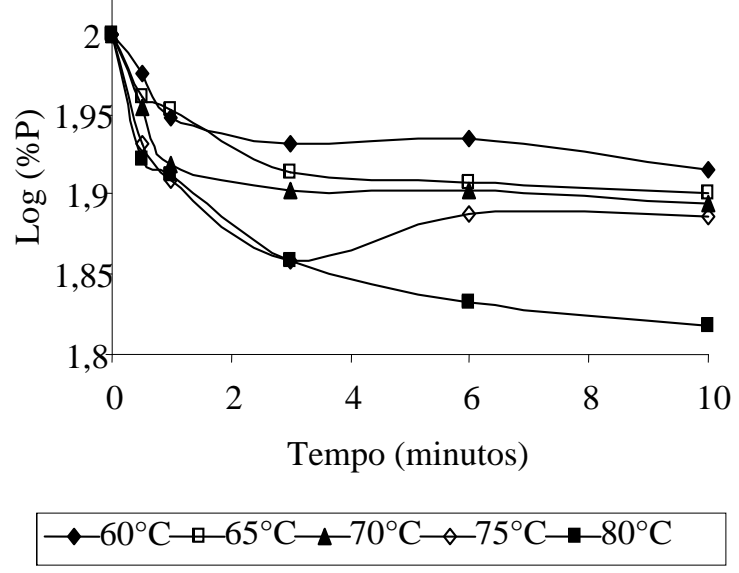

a)

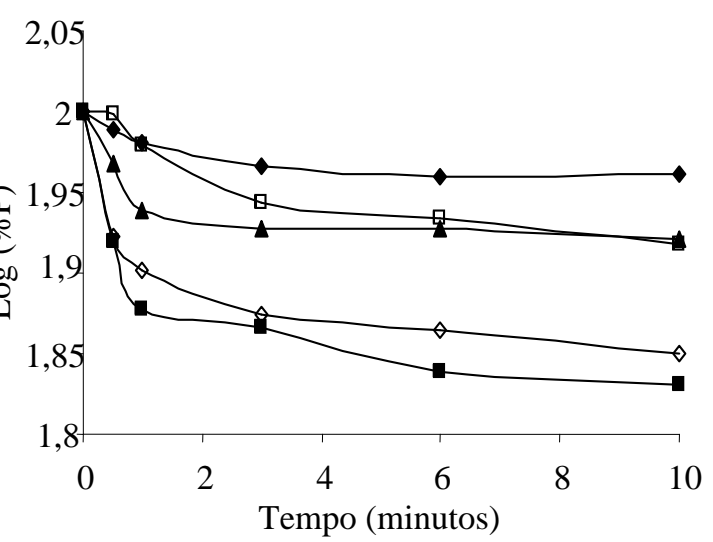

$-60^{\circ} \mathrm{C} \_-65^{\circ} \mathrm{C} \_-70^{\circ} \mathrm{C} \multimap-75^{\circ} \mathrm{C} \longrightarrow-80^{\circ} \mathrm{C}$

b)

Figura 2 - Inativação térmica da POD de polpa de abacate (Variedade Choquete) a 60, 65, 70, 75 e $80^{\circ} \mathrm{C}$. (a - Abacate Verde, b - Abacate Maduro).

Os estudos da inativação térmica apresentam mudança na inclinação das curvas, indicando a presença de duas porções das enzimas, uma termolábil e outra termorresistente.

Nas figuras 1, 2 e 3 pode-se observar o efeito da temperatura sobre o tempo necessário para a inativação térmica das enzimas PPO, POD e PIN, pois conforme a temperatura aumentava, o tempo de aquecimento para inativação diminuía, fato esse também observado no comportamento da porção termolábil dessas enzimas.

Através dos parâmetros cinéticos ( $\mathrm{D}, \mathrm{K}$ e $\mathrm{Z}$ ) calculou-se a EA, cujos valores estão na tabela 5 e 6. 


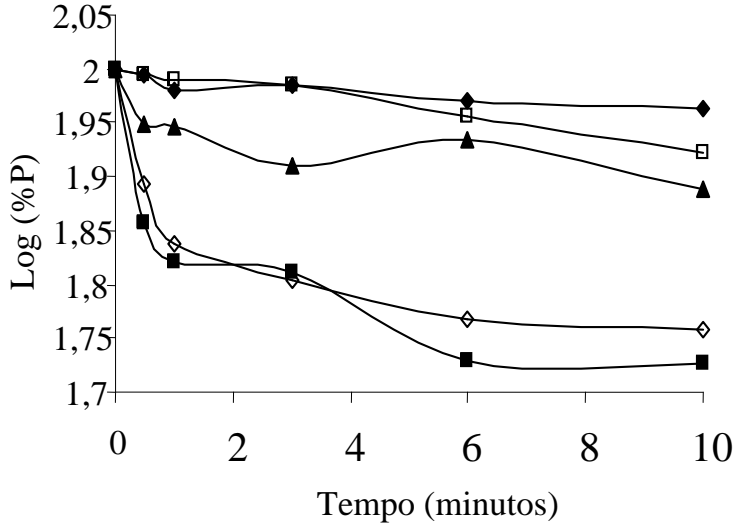

$-60^{\circ} \mathrm{C} \rightarrow 65^{\circ} \mathrm{C} \_70^{\circ} \mathrm{C} \triangleleft 75^{\circ} \mathrm{C} \rightarrow-80^{\circ} \mathrm{C}$

a)

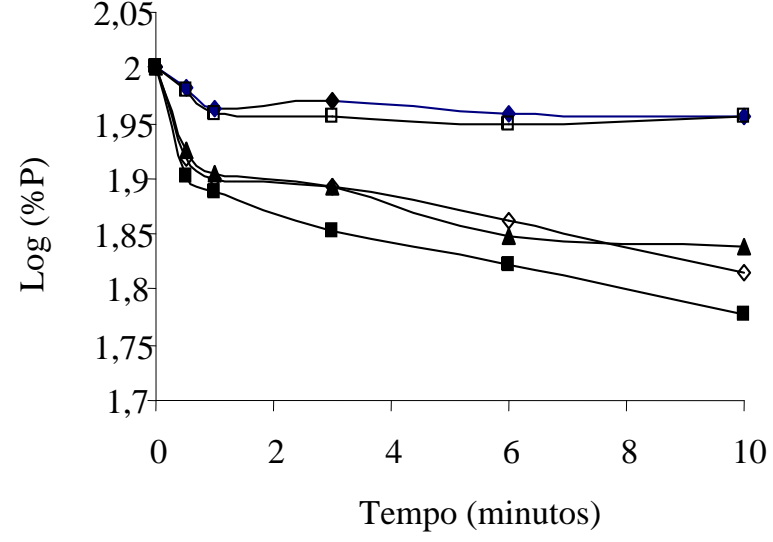

$60^{\circ} \mathrm{C} \square-65^{\circ} \mathrm{C}-70^{\circ} \mathrm{C} \diamond-75^{\circ} \mathrm{C}-80^{\circ} \mathrm{C}$

b)

Figura 3 - Inativação térmica da PIN de polpa de abacate (Variedade Choquete) a $60,65,70,75$ e $80{ }^{\circ} \mathrm{C}$. (a - Abacate Verde, b - Abacate Maduro).

Tabela 5 - Valores da Energia de Ativação das porções termolábil e termorresistente da PPO da polpa de abacate.

\begin{tabular}{cccc}
\hline \multirow{2}{*}{ VariedadelEstádio de maturação } & \multirow{2}{*}{ Enzima } & \multicolumn{2}{c}{ Energia de Ativação (kcal/mol) } \\
\cline { 3 - 4 } & & Porção Termolábil & Porção Termorresistente \\
\hline Quintal Verde & PPO & 22,82 & 22,82 \\
Quintal Maduro & PPO & 21,47 & 21,20 \\
Fortuna Verde & PPO & 14,63 & 15,07 \\
Fortuna Maduro & PPO & 11,25 & 11,19 \\
Choquete Verde & PPO & 22,98 & 22,71 \\
Choquete Maduro & PPO & 13,01 & 13,02 \\
\hline
\end{tabular}

Tabela 6 - Valores da Energia de Ativação das porções termolábil e termorresistente da POD e PIN da polpa de abacate.

\begin{tabular}{cccc}
\hline \multirow{2}{*}{ VariedadelEstádio de Maturação } & \multirow{2}{*}{ Enzima } & \multicolumn{2}{c}{ Energia de Ativação (kcal/mol) } \\
\cline { 3 - 4 } & & Porção Termolábil & Porção Termorresistente \\
\hline \multirow{2}{*}{ Choquete Verde } & POD & 8,13 & 8,13 \\
& PIN & 21,63 & 21,25 \\
\multirow{2}{*}{ Choquete Maduro } & POD & 13,02 & 12,97 \\
& PIN & 23,03 & 22,98 \\
\hline
\end{tabular}

Os valores de energia de ativação encontrados para as porções termolábil e termorresistente da polifenoloxidase e peroxidase, fração solúvel e ionicamente ligada, estão entre $10-23 \mathrm{kcal} / \mathrm{mol} \mathrm{e} 8-25 \mathrm{kcal} / \mathrm{mol}$, respectivamente. Segundo Sgarbieri (1996) os valores de energia de ativação para a destruição de enzimas estão entre $12-100 \mathrm{kcal} / \mathrm{mol}$. A energia de ativação para a desnaturação de enzima apresenta uma grande variação (12-100 kcal/mol), indicando a presença de isoenzimas de variável resistência térmica. Logo, a energia de ativação nas temperaturas estudadas está dentro da faixa $12-100 \mathrm{Kcal} / \mathrm{mol}$ reportada para o processo de inativação térmica de enzimas. 


\section{CONCLUSÃO}

Nas condições do experimento, dentre as variedades estudadas, a variedade que apresentou menor atividade enzimática na polpa foi a Fortuna, o que a destacaria entre as outras para um processo de industrialização.

\section{AGRADECIMENTOS}

Ao Engenheiro Agrônomo Sabino Leonides Moteka pelo fornecimento dos frutos da Fazenda Experimental do Campus Regional de Diamante do Norte/UEM.

\section{REFERÊNCIAS BIBILIOGRÁFICAS}

ARAÚJO, J. M. A. Química dos alimentos. Viçosa: UFV, 1999.

BOBBIO, F. O.; BOBBIO, P. A. Introdução à química dos alimentos. 2. ed. São Paulo: Varela, 1992.

CLEMENTE, E. Purification and thermo stability of isoperoxidase from oranges. Phytochemistry, Oxford, v. 49, n. 1, p. 29-36, 1998.

EVANGELISTA, J. Tecnologia de alimentos. 2. ed. São Paulo: Atheneu, 1998.

FORTUNATO, A. A. Estudo da cinética de inativação da pectinesterase e da peroxidase presentes na polpa de cajá (Spondias lútea). 2002. 76 f. Dissertação (Mestrado) - Universidade Federal do Rio Grande do Norte, Natal, 2002.

FUJITA, S.; SAARI, N.; MAEGAWA, M.; TETSUKA, T.; HAYASHI, N.; TONO, T. Purification and properties of polyphenol oxidase from cabbage (Brassica oleracea L.). Journal of Agricultural and Food Chemistry, Washington, v. 43, p. 1138-1142, 1995.

LING, A. C.; LUND, D. B. Determining kinectics parameters for thermal inactivation of heat resistant and heat labile isoenzymes from thermal destruction curves. Journal of Food Science, Chicago, v. 43, p. 1307-1310, 1978.

LUND, D. B. Heat processing. In: Principles of food science: part II: principles of food preservation. New York: M. Dekker, 1975.

RAMASWAMAMY, H. S.; VOORT, F. R. van de; GHAZALA, S. An analysis of TDT and arrhenius methods for handling process and kinectic data. Journal of Food Science, Chicago, v. 54, p. 1322-1326, 1989.

SGARBIERI, V. C. Proteínas em alimentos protéicos: propriedades, degradações, modificações. São Paulo: Varela, 1996. 